\title{
Má-consciência, crueldade e 'narcisismo às avessas' no cinema brasileiro contemporâneo
}

\section{Fernão Pessoa Ramos*}

\section{Resumo}

Neste texto o autor chama de má-consciência da classe média brasileira as formas de representação do popular (favela, carnaval e outras manifestações da vida social), no cinema brasileiro atual.

Palavras-chave: cinema brasileiro, povo, má consciência.

"A nossa modéstia começa nas vacas (...). Cabe então

a pergunta - e por que até as vacas brasileiras reagem assim? O mistério me parece bem transparente.

Cada um de nós carrega um potencial de santas humilhações hereditárias. Cada geração transmite

à seguinte todas as suas frustrações e misérias.

No fim de certo tempo, o brasileiro tornou-se um Narciso às avessas, que cospe na própria imagem. Eis a verdade - não encontramos pretextos pessoais ou históricos para a auto-estima. Se não me entenderam, paciência. E tudo nos assombra. Um simples 'bom dia' já nos gratifica”.

Nelson Rodrigues (Crônica "A Vaca Premiada", da coletânea "A Cabra Vadia")

* Fernão Ramos é professor de cinema na Unicamp, publicou Cinema Marginal (1968/1973): a representação em seu limite (SP, Brasiliense, 1986), História do Cinema Brasileiro (SP, ArtEditora, 1987) e Enciclopédia do Cinema Brasileiro (SP, Ed. SENAC, 2000).

Comun. Inf., v. 5, n. 1/2, p.13-24, jan./dez. 2002 
A fratura de classes da sociedade brasileira está presente de modo recorrente em nosso cinema. Expressa-se no que podemos chamar "representação do popular". Depois do intervalo da década de 80 (quando a produção nacional mais criativa estabelece um diálogo fechado com o cinema de gênero) retornam no cinema brasileiro contemporâneo os clássicos motivos da representação do popular (a favela, o sertão, o carnaval, o candomblé, o futebol, o folclore nordestino). Vemos, outra vez, a fisionomia do povo na tela. Alguns elementos diferenciais, no entanto, marcam essa retomada.

O eixo que orienta a questão ética na representação do popular no Cinema Brasileiro, a partir dos anos 60, é o sentimento de má-consciência. Essa má-consciência está relacionada ao fato de essa representação do popular ser a representação de um "outro", a assunção de uma voz que não é a de quem a emite. Trata-se de uma rachadura que, seguindo a sensibilidade da Antropologia Visual, poderíamos chamar de epistemológica. Em sua complexidade contemporânea, já pode ser sentida em todasuaintensidade em Deus e o Diabo na Terra do Sol (1963), tomando sua feição mais precisa em Terra em Transe (1966). Este é o filme no qual eclode a contradição ética intrínseca à representação do popular como "outro", dilema que compõe o fulcro central da obra de Glauber Rocha. No campo do pensamento sobre cinema, o livro Brasil em Tempo de Cinema (Civilização Brasileira, 1967), de Jean-Claude Bernardet, sente nitidamente a pressão dessa rachadura epistemológica e a constata em tom recriminatório: este "outro" que representa o povo, que possui ambições de um saber pelo povo, nada mais é do que a classe média olhando para seu próprio umbigo. Temos um cinema de classe média, em vez de um cinema popular, e isto incomoda a geração que fez o Cinema Novo. "Já imaginaram Gerônimo no poder?", nos diz o protagonista de Terra em Transe, Paulo Martins (Jardel Filho), com um lider sindical nas mãos e olhando fixo para o espectador, encarnando as desconfianças e angústias dessa alteridade. Pois "Gerônimo" hoje chegou ao poder e o Cinema Brasileiro ainda debate-se com sua sombra, na forma de uma má-consciência.

Neste artigo vamos dar um nome à expressão contemporânea dessa má-consciência: a chamaremos de "narcisista às avessas", e vamos considerar que sua manifestação embute uma forma de crueldade. A má-consciência para com a alteridade popular, hoje, desloca-se, e ao querer negar-se assume uma postura acusativa. As dúvidas para com o potencial do povo e sua cultura (presentes no primeiro Cinema Novo

Comun. Inf., v. 5, n. 1/2, p.13-24, jan./dez. 2002 
e, em particular, nos longas de Glauber da década de 60) desaparecem para serem substituídas pela imagem idealizada desse mesmo povo. Na outra ponta do pólo popular, no pólo negativo, não está mais a classe média, mas a nação como um todo e, em particular, o estado e suas instituições. Estabelece-se, então, a dualidade maniqueísta, povo idealizado/estado incompetente, que percorre a produção da chamada Retomada. A satisfação e a catarse espectatorial realizam-se às custas dessa polaridade, na forma de um "masoquismo primário" que, seguindo Nelson Rodrigues, chamaremos de "narcisismo às avessas". A tendência é que, a partir de $1^{\circ}$ de janeiro de 2003 , dilua-se progressivamente a agressividade com que esta oposição aparece. Filmes mais recentes, como Deus É Brasileiro, já apontam para uma superação da situação limite traçada neste artigo.

Estamos nos referindo às estratégias desenvolvidas por filmes-chave da Retomada, para promover emoções no espectador, por meio de mecanismos de catarse que incidem sobre uma representação, acentuadamente negativa, de aspectos da vida social brasileira. Em uma rota de fuga, a satisfação catártica desse espectador não se direciona mais para o universo representado propriamente, mas identifica-se com a postura acusatória que a narrativa sustenta, como instância enunciadora. A postura acusatória ante a nação incompetente, emerge como a prova do não pertencimento ao universo sórdido representado. Rimos e nos admiramos com esse universo, mas não é nossa a responsabilidade, pois estamos, junto com a narrativa, também acusando. Se a nação como um todo e, em particular, o estado brasileiro são cobertos com "estatuto da incompetência", aquele que acusa marca, pela iniciativa de acusar, seu não pertencimento à comunidade dos incompetentes.

Esse é o prazer perverso, embutido na volúpia de representar o sórdido, que percorre o cinema brasileiro contemporâneo. Podemos identificar uma espécie de "naturalismo cruel" que percorre a produção contemporânea, tanto em sua vertente ficcional, como em sua produção de cunho documentário. Seja segundo uma perspectiva mais intimista, ou seja, a partir da má-consciência social do narcisista às avessas, a representação naturalista cruel aparece em obras-chave da produção cinematográfica brasileira dos últimos dez anos: de Central do Brasil à Cronicamente Inviável, passando por documentários como Notícias de Uma Guerra Particular; Boca do Lixo; Os Carvoeiros; Mamazônia, A Última Floresta; O Rap do Pequeno Prín-

Comun. Inf., v. 5, n. 1/2, p.13-24, jan./dez. 2002 
cipe contra as Almas Sebosas; Ônibus 174; e O Prisioneiro da Grade de Ferro. Também a encontramos em Orfeu; O Primeiro Dia; Dezesseis Zero Sessenta; Como Nascem os Anjos; Um Céu de Estrelas; O Cego que Gritava Luz; A Grande Noitada; Bocage, o Triunfo do Amor; Estorvo; Um Copo de Cólera; Lavoura Arcaica; Bicho de Sete Cabeças; Latitude Zero. No pioneiro Carlota Joaquina, princesa do Brasil ou ainda nos recentes Uma Onda no Ar, O Príncipe, O Invasor, Dois Perdidos em uma Noite Suja, ou nos dois últimos grandes sucessos de público da produção nacional, Cidade de Deus e Carandiru. Em sua gama diversa, esse "naturalismo cruel" pode ser definido pelo prazer que toma a narrativa em deter-se na imagem da exasperação ou da agonia. São constantes os longos planos dedicados à representação de berros ou momentos de crise existencial. A exasperação dramática é mostrada em detalhe $\mathrm{e}$ exagerada ao extremo, para além da motivação realista. $\mathrm{O}$ deboche, os personagens sórdidos, os risos histéricos são representados em destaque, de modo lento e prolongado. A imagem da miséria, da sujeira, a ação dramática em ambientes fechados e abafados (como prisões ou favelas) surgem de modo recorrente. Mortes, sangue, ações com requintes cruéis de violência são exibidos em toda sua crueza. Essa imagem constitui-se segundo uma estratégia que eleva a intensidade ao limite da agressão ao espectador. O naturalismo cruel incomoda, agri$\mathrm{de}$, provoca constrangimento e considera esse constrangimento um trunfo. À estratégia do espectador para obter prazer nessa situação chamamos de "narcisismo às avessas". O naturalismo cruel costumar sair da esfera intimista-psicologizante (na qual em diversos casos, permanece) para cristalizar-se na representação de uma nação socialmente cindida. Os filmes em que isso ocorre é o que nos interessa aqui.

A composição do naturalismo cruel com o narcisismo às avessas marca um percurso que embute uma forma de recepção. O genial da expressão rodrigueana ("o brasileiro tornou-se um narciso às avessas, que cospe na própria imagem") é conseguir resumir um traço essencial de sua própria obra (onde a crueldade excele) à forma de recepção que dela pressente: o caráter humilde, bovino, no limite masoquista, da personalidade do brasileiro, espectador ideal para ter prazer com a cascata iconoclasta de seus dramas (Plínio Marcos também não é estranho a este recorte). O gosto, o prazer "narcisista" (a ironia rodrigueana aqui é clara) que o brasileiro tem em cuspir na própria

Comun. Inf., v. 5, n. 1/2, p.13-24, jan./dez. 2002 
imagem, é expresso com humor em uma figura recorrente de suas crônicas futebolísticas: a intensidade e a facilidade (singular, segundo o autor, no cenário das nações) com as quais vaia-se o símbolo único, no qual a nação realmente se destaca: a "seleção".

Retomando o percurso esboçado: existe uma dimensão cruel no cinema nacional contemporâneo e essa crueldade embute uma agressividade - na forma do narcisista às avessas de Nelson - às instituições e ao estado brasileiro (em particular), ou ao Brasil e ao "brasileiro" (em geral). Aventamos a hipótese de que uma representação de caráter dual e maniqueísta (estado incompetente/povo idealizado), acompanhando um motivo recorrente da história do cinema brasileiro (a má-consciência própria à representação do popular e dos temas que lhe são correlatos), constitua uma forma dramática hoje predominante, dando vazão a um mecanismo narrativo tradicional de catarse e identificação do espectador.

Vejamos, de modo mais detido, como esse universo maniqueísta se expressa em um eixo temático preciso. Dois grupos podem serem destacados, dentre outros (deixamos de lado o intimismo dilacerado de Um Copo de Cólera, Latitude Zero, Estorvo, Um Céu de Estrelas, Lavoura Arcaica): os filmes que expõem a representação das mazelas da nação ante o personagem anglo-saxão (dicotomia estrangeiro idealizado/nação incompetente) e os que centram a construção naturalista cruel acentuando a oposição povo idealizado/nação incompetente. Os dois grupos não são estanques entre si.

No primeiro caso, colocamos os filmes Carlota Joaquina, Princesa do Brasil, Como Nascem os Anjos e O Que É Isso Companheiro?. No segundo, são emblemáticos Central do Brasil, Notícias de uma Guerra Particular, Orfeu e Cronicamente Inviável. Filmes mais recentes, como Cidade de Deus e Carandiru adequam-se plenamente a uma análise centrada nessas categorias, mostrando sua pertinência.

A representação do estatuto da incompetência nacional percorre Carlota Joaquina, Princesa do Brasil de ponta à ponta. A essência do Brasil aparece mostrada no universo baixo e servil da corte portuguesa, que contamina irremediavelmente nossas origens. Já os personagens anglo-saxões exercem duplamente seu papel moderador. $\mathrm{O}$ narrador escocês, além do poder de origem que a enunciação lhe confere, diverte-se e espanta-se com a incompetência segundo a qual desenrola-se o quadro histórico tupiniquim. No universo diegético é o

Comun. Inf., v. 5, n. 1/2, p.13-24, jan./dez. 2002 
diplomata inglês que domina a situação política de maneira altiva. Defende de modo preciso seus interesses, percorrendo com agilidade a eterna balbúrdia e as orgias nas quais mergulham os dirigentes lusobrasileiros. Nesse momento-chave de nossa fundação como nação, a referência anglo-saxã serve como parâmetro para medirmos nossa incompetência. Também característico é o prazer exibicionista (autênticamente "narcisista às avessas") com que o traço de inferioridade é figurado. $\mathrm{O}$ tom é de autêntica humildade, restando, ao incompetente, o prazer de divertir a ponderação do estrangeiro que avalia. Uma fala oculta parece repetir: "Que ao menos valorizem nossas trapalhadas, pois elas são inocentes, infantis, e só querem o espaço marginal de aprovação que é próprio do riso".

Em Como Nascem os Anjos, o estatuto da incompetência é figurado, de modo dual, entre os pólos povo positivo/estado negativo. E também aqui a figura do personagem anglo-saxão surge exercendo seu poder moderador, diante da nação brasileira exposta em suas misérias. O lado institucional dessa nação, a polícia, é mostrada em oposição às demandas ponderadas e humanistas do americano, mantido como refém, que solicita a presença de ONGs para evitar o assassinato dos menores e também de uma Comissão de Direitos da Criança quando de seu resgate. A atividade da polícia é evidenciada como exemplo de incompetência, preconceito e irracionalidade. Também a mídia nacional é apresentada no mesmo tom. No lado "popular" da história, predominam personagens que não conseguem articular de modo coerente suas demandas: duas crianças volúveis e um bandido no limite da loucura. Este bandido, personagem meio bobo, gritando muito e de modo irritante, responde a uma tradição antiga do Cinema Brasileiro que remonta ao Cinema Marginal nos anos 60. Salles recupera esse tipo, como forma de lidar e representar o universo popular do morro, preparando-o para a interferência "construtiva" do personagem anglo-saxão. O filme desloca o conflito para o aspecto institucional da nação (a brutalidade policial), buscando preservar o lado "popular". A figuração do universo do morro, por meio de um bandido retardado e duas crianças inseguras, parece ter a função de fazer com que a contraposição estrangeiro/nação incompetente realize-se de modo inteiramente favorável ao primeiro. Um personagem popular mais espesso e coerente comprometeria a polaridade maniqueísta e a postura narcisista às avessas. $\mathrm{O}$ bandido retardado é, na realidade, a configuração de um mal-estar, que se delineia logo nas

Comun. Inf., v. 5, n. 1/2, p.13-24, jan./dez. 2002 
primeiras cenas. Configura uma visão masoquista da sociedade brasileira que oferece o que existe nela de pior para o exercício da condescendência do personagem anglo-saxão, com o qual o espectador se identifica.

A constelação da postura humilde diante do personagem estrangeiro encontra-se igualmente em $O$ Que É Isso Companheiro?, de Bruno Barreto. O diplomata americano seqüestrado possui a única voz sensata, em meio a adolescentes desvairados, torturadores e militares autoritários. Personagem de maior densidade do filme, o embaixador norte-americano é o único a ter conflitos existenciais que permitem uma evolução complexa de sua personalidade. Apesar de representante da nação imperialista, desenvolve uma simpatia humanista pelos seqüestradores, interessando-se pela bibliografia esquerdista apresentada, além de possuir uma delicada visão poética de sua situação, ao descrever, por exemplo, a pele e as mãos dos seqüestradores. Estes, ao contrário, são bem mais planos. Encarnam tipos particulares (o durão, a mocinha, o intelectual, o menino deslumbrado), servindo como parâmetro para o estabelecimento de eixos, por meio dos quais o personagem do embaixador cresce. $\mathrm{O}$ único seqüestrador que poderia concorrer em maturidade e complexidade com a personalidade do embaixador, o personagem do velho líder comunista que supervisiona a operação, permanece em plano secundário, sem nenhum desenvolvimento. Odeslumbramento com o universo ideológico da contracultura norte-americana e a elegia à postura existencial do liberal anglo-saxão constituem o ponto de vista escolhido pelo filme para retratar o momento histórico capital vivido pelo Brasil naquele instante. A representação da incompetência do grupo brasileiro no planejamento e realização do seqüestro é explícita.

A postura humilde diante do personagem estrangeiro, fazendo dupla com a exibição da cultura popular, é recorrente em outros filmes da produção da Retomada, podendo ser detectada em Bela Donna, de Fábio Barreto; For All - trampolim da vitória, de Luiz Carlos Lacerda e Buza Ferraz; Natal da Portela, de Paulo César Sarraceni; Jenipapo, de Monique Gardenberg. Em Amélia, de Ana Carolina, a postura humilde é mais tencionada e o quadro do narcisista às avessas não surge tão claramente. A dupla caipira desenvolve estratégias concretas para enfrentar e driblar a opressão da prima-donna européia. O documentário Banana is My Business, de Helena Solberg, constitui uma exceção nesse quadro, retratando a humilhação de Carmen

Comun. Inf., v. 5, n. 1/2, p.13-24, jan./dez. 2002 
Miranda e, de modo negativo, a humildade nacional diante da arrogância anglo-saxã. Nesse filme a satisfação narcissista às avessas não decola.

Se a dicotomia 'personagem anglo-saxão idealizado/Brasil inviável' exemplifica bem a dimensão humilde do narcisismo às avessas, a segunda dualidade apontada, entre 'povo idealizado/estado incompetente', marca de modo mais emblemático a representação naturalista cruel. Três filmes-chave da produção contemporânea, Central do Brasil, Orfeu e Cronicamente Inviável, articulam-se de modo emblemático, atualizando, em uma expressão contemporânea, os dilemas próprios à "ruptura epistemológica" povo/classe média dos anos 60. O ponto que realçamos aqui é o retorno da temática da representação do popular (sua cultura, sua fisionomia voltam à tela), relacionando-o à postura humilde do espectador, na forma de um narcisismo às avessas. Essa postura humilde constitui-se por meio da crítica acirrada à incompetência do estado brasileiro, contraposta à idealização do popular. O narcisista às avessas nega-se por meio da elegia idealizada do outro (por isso é humilde) e se redime na catarse dessa idealização.

Em Central do Brasil, a má-consciência da protagonista (Dora) para com o povo humilde é evidente e sua oscilação constituirá o principal móvel dramático do filme. Trair ou não trair o povo é um dilema presente de forma recorrente no cinema brasileiro dos anos 60 . Na década de 90, a tragédia existencial-política é mais rala e melodramática. Em Central do Brasil, o percurso da narrativa é claro. Parte de uma visão do país que é acentuada em seu negativismo, para, em seguida, desenvolver um movimento de redenção pela catarse da piedade. O mais cruel dos crimes (o assassinato de crianças pobres para extração de órgãos) surge como algo corriqueiro na "central", no coração do Brasil. Aos pequenos crimes de Dora, sobrepõe-se esse, maior em escala, em cuja participação existe um "quê" de ação cotidiana banal. Também na "Central", o assassinato de crianças que cometem pequenos furtos é corriqueiro. O motor da ação, que irá configurar a má-consciência de Dora, é concebido para ser pesado ao extremo, refletindo a necessidade de mostrar um quadro de sordidez no qual o país está mergulhado. Dora é movida pela má-consciência, figurando em si o sentimento de classe dos diretores do filme (e de boa parte do público), com relação ao universo popular que circula na Central do Brasil.

Comun. Inf., v. 5, n. 1/2, p.13-24, jan./dez. 2002 
A figuração da má-consciência, no entanto, parece ser excessivamente incômoda para ser deixada nessa forma, sem um horizonte no qual possa ser resgatada. E é a este resgate que se dedica a segunda parte do filme. Dora é purgada de suas oscilações sobre o sacrifício do menino na seqüência da procissão, quando mergulha fisicamente no povo e encontra-se embebida em sua fé e sua cultura. Um dos momentos-chave do filme, a sequência da procissão, traz a comoção pessoal vivenciada internamente, produzindo como resultado a conversão definitiva da protagonista ao menino. A virada é bem marcada e a dimensão conflitiva que impedia o congraçamento do espectador com a causa popular desaparece do horizonte. Até a atriz Fernanda Montenegro está agora mais à vontade para realçar seu personagem. Por meio da catarse pela piedade, explora-se o dilatado espaço entre a sordidez do crime pensado e o tamanho da conversão. Com a catarse, a narrativa resgata a passividade dos personagens para com a dimensão sórdida da nação, que assassina suas crianças ou as trafica para o exterior. É a nação inviável que recebe o ônus de sustentar a conformação dos pólos extremos da equação, necessários para a figuração da catarse pela piedade: "congraçamento na negação do pertencimento à nação inviável" (e minha adesão à postura crítica é a prova de que não pertenço à coletividade incompetente) versus "congraçamento na piedade do povo idealizado". O naturalismo cruel serve como estilística que acentua as dicotomias. É interessante notar aqui como a postura narcisista às avessas abre espaço para a constelação de emoções de caráter exaltativo.

Em Orfeu (99), de Cacá Diegues, a representação da cultura popular compõe o eixo dramático do filme como pólo opositor à sordidez que cerca a dimensão institucional da nação. É interessante notar a volta de Cacá a um tema que, no final dos anos 50, conformou um consenso, para o Cinema Novo, em torno de como não tratar a cultura popular. O "Orfeu" de Camus (Orfeu do Carnaval, 1959) encarnava a postura humilde do popular folclórico que se oferece à fruição do espectador estrangeiro. No segundo Orfeu, o clima idílico do morro do primeiro filme é completamente deixado de lado. Temos no horizonte o quadro negro da nação inviável, representada pela polícia corrupta e insensível. O sargento é preconceituoso, violento e advoga, entre outras coisas, a esterilização dos pobres e seu extermínio. Orfeu afirma explicitamente que esse tipo de polícia é "a única coisa do estado que sobe o morro". A cultura popular aparece como manifestação

Comun. Inf., v. 5, n. 1/2, p.13-24, jan./dez. 2002 
idílica de resgate da identidade, a partir da qual instaura-se o mito de Orfeu e o tom fantasista que permeia o universo ficcional positivo. A favela idílica do primeiro Orfeu desaparece para dar lugar à representação da nação inviável, mas o lado idealizado da cultura popular permanece. Esse é o deslocamento central exercido no mito pelo segundo Orfeu, ao qual devemos acrescentar uma cisão do universo popular, agora também representado em seu lado negro (a violência do grupo de traficantes, incorporando a figura mítica da Morte). No entanto, mesmo nessa dimensão negativa, o recorte do popular possui uma ética de valores que é negada aos agentes institucionais do estado, permitindo o estabelecimento do pólo negativo necessário para a identificação redentora que modula a crua intensidade do naturalismo cruel.

Cronicamente Inviável é a obra que conseguiu delinear de modo mais preciso o estatuto da incompetência do estado brasileiro, carregado de crueldade no detalhamento da representação do sórdido. A representação do popular não está aqui no eixo central do filme, construindo a oposição redentora ao estado incompetente. A figuração da incompetência é horizontal. Todos são acusados. Não se abre uma exceção na qual o espectador consiga sustentar-se para salvar qualquer intuito de identificação. Não encontramos a porta para a recuperação do ego pela catarse na figura do popular idealizado. Tampouco está presente a figura redentora do personagem anglo-saxão. A nação como um todo é inviável e o filme vai percorrendo, um a um, seus agentes sociais, querendo demonstrar essa tese. Do movimento dos sem-terra, passando pelas lideranças indígenas, movimento negro, jornalistas, homossexuais, burguesia, professores, ONGs, centros de caridade, projetos alternativos de recuperação de menores, todos são reduzidos à evidência da incompetência, do oportunismo e das intenções sórdidas. Qualquer tentativa pontual de se lidar de forma positiva com o caos social é desconstruída com uma ponta de prazer.

Cronicamente Inviável, no entanto, abre espaço para uma postura espectatorial cômoda. A crítica acirrada, em sua horizontalidade, estabelece o eixo redentor de identificação com a voz narrativa que enuncia a acusação. Uma vez nessa posição, podemos nos direcionar, sem má-consciência, à coletividade inviável, pois está provado que dela não fazemos parte (a prova é que a criticamos acirradamente), e confortavelmente nos instalarmos na humildade narcisista às avessas. Trata-se do mecanismo descrito de embate (e defesa) com o naturalis-

Comun. Inf., v. 5, n. 1/2, p.13-24, jan./dez. 2002 
mo cruel. É interessante notar que o próprio filme e os cineastas que o compuseram estão excluídos da metralhadora iconoclasta que percorre a sociedade brasileira. Está ausente do filme qualquer dimensão reflexiva que tematize a enunciação do quadro exibido. Com efeito, a postura crítica não pode abarcar a instância enunciadora dessa mesma crítica, no caso, o filme em si mesmo. À medida que isso se configura, o círculo se abre e o exercício da redenção, mediante a exclusão do pertencimento, estará dificultado. A representação negativa da nação dilacerada em Cronicamente Inviável permite um tipo de satisfação do espectador que embute uma identificação com a coletividade próxima da representação nacionalista exaltada, com o narcisismo às avessas beirando um nacionalismo às direitas. .

O fato de em Cidade de Deus, de Fernando Meirelles e Kátia Lund, não figurar a dualidade povo idealizado/estado incompetente como eixo redentor do naturalismo cruel, talvez esteja na raiz das reações desencontradas que provoca. Em Cidade de Deus, o pólo "estado brasileiro" continua a ser definido de modo negativo. Não ocupa, no entanto, no filme, a função de resgate emocional pela crítica, estabelecendo, assim, o contraste com o idealizado pólo positivo-popular. Isso incomoda, pois a postura humilde, embutida no narcisismo às avessas, não consegue se realizar em sua plenitude. Nesse filme, a mistura da cultura popular com elementos da contracultura dos anos 60 (uma cultura essencialmente de classe média) e com a cultura de massa veiculada pela mídia é um dos fatores na quebra da dualidade. Os personagens de classe média também não se configuram em clara oposição ao eixo popular (o personagem da jornalista, por exemplo). O povo em Cidade de Deus não é bonzinho, nem a exibição de sua cultura tradicional (samba, candomblé, futebol) ocupa espaço de destaque. $\mathrm{Na}$ realidade, a representação naturalista cruel atinge também o eixo do popular e não há resgate como em Orfeu ou Central do Brasil. Em uma das imagens marcantes do naturalismo cruel no cinema brasileiro contemporâneo, o filme representa em detalhes o assassinato e a tortura de duas crianças. A função do detalhamento da cena parece ser a de um puro sadismo agressivo para com o espectador. O salto clássico do narcisismo às avessas em busca da redenção está dado, mas não é apertado seu laço no pólo 'estado incompetente'.

Em Carandiru, o movimento já é mais clássico e podemos delinear a temática do estado incompetente, como eixo catártico. Babenco é um cineasta argentino que sempre teve uma caída para o lacrimoso, ao

Comun. Inf., v. 5, n. 1/2, p.13-24, jan./dez. 2002 
representar o lado sórdido da realidade social brasileira. Em Carandiru, a última meia hora do filme parece estar à vontade para a representação do Brasil infame que já encontramos em Pixote, a lei do mais fraco; Lucio Flávio, o passageiro da agonia; O Beijo da Mulher Aranha; Brincando nos Campos do Senhor. A cena do massacre, na qual é dada vazão plena ao detalhamento naturalista cruel, começa com a entoação do hino nacional na partida de futebol e termina com Aquarela do Brasil, logo no ínicio dos créditos. O Brasil dos coqueiros que dão côco e das noites claras de luar não pode ser deixado em paz. O embate com o choque que a representação naturalista do massacre provoca é modulado pelo endosso da ironia fácil que, por meio da canção, contrapõe o Brasil idílico ao Brasil cruel do estado incompetente. Essa necessidade recorrente de identificação na postura crítica (de novo Nelson), exacerbada dramaticamente pela representação cruel, é, sem dúvida, testemunha de um mal-estar social, ao qual chamamos de má-consciência. Trata-se de uma forma de purgação (sinônimo de 'catarse' para a estética clássica) de uma classe média perplexa, diante de uma realidade social dilacerada pela qual se sente, além de amedrontada, responsável.

\section{Abstract}

In this text the author calls the Brazilian middle class bad consciousness the ways the people and its way of life (slams, carnival and other characteristics) are represented in the Brazilian contemporary cinema.

Keywords: Brasilian cinema, popular way of life, bad consciousness.

Comun. Inf., v. 5 , n. 1/2, p.13-24, jan./dez. 2002 